\title{
Respiratory symptoms in children and exposure to pesticides
}

\author{
P.R. Salameh*, I. Baldi", P. Brochard", C. Raherison", B. Abi Saleh*, R. Salamon"
}

Respiratory symptoms in children and exposure to pesticides. P.R. Salameh, I. Baldi, P. Brochard, C. Raherison, B. Abi Saleh, R. Salamon. (C) ERS Journals Ltd 2003.

ABSTRACT: In Lebanon, childhood asthma is an important disease and pesticides are commonly used. The objective of this study was to evaluate whether exposure to pesticides has chronic effects on the respiratory health of Lebanese children.

A cross-sectional study was performed on children from a randomly selected sample of Lebanese public schools. Exposure to pesticides was evaluated by a standardised questionnaire and a residential exposure score, and respiratory symptoms were assessed by using the American Thoracic Society standardised questionnaire.

A chronic respiratory disease was reported in 407 (12.4\%) out of 3,291 children. The baseline difference in mean age was small but statistically significant. Any exposure to pesticides, including residential, para-occupational and domestic, was associated with respiratory disease and chronic respiratory symptoms (chronic phlegm, chronic wheezing, ever wheezing), except for chronic cough.

Exposure to pesticides was associated with chronic respiratory symptoms and disease among Lebanese children.

Eur Respir J 2003; 22: 507-512.
*Faculty of Public Health, Lebanese University, Fanar, Lebanon. ${ }^{\#}$ Faculty of Public Health, Institute of Public Health, Epidemiology and Development, Victor Segalen Bordeaux 2 University, Bordeaux, France.

Correspondence: P. Salameh, Jdeidet El Meten, Chalet Suisse Str., Ramza Azzam Bldg, 5th floor, Beirut, Lebanon.

Fax: 9619934164

E-mail: pascalesalameh@yahoo.com

Keywords: Asthma, domestic, exposure, paraoccupational, pesticides, respiratory

Received: November 252002

Accepted after revision: April 232003
Childhood asthma is one of the most important diseases of childhood, causing substantial morbidity [1] and a growing public health concern in low-income communities [2]. Passive smoking, the possession of animals, living in an urban setting, growing-up in a farming environment and allergen exposures are considered environmental predictors of asthma and bronchial hyperresponsiveness among children [3, 4].

In Lebanon, little is known about the prevalence of asthma and allergic diseases in children. Following the International Study of Asthma and Allergies in Childhood (ISAAC) design, a study conducted on 13-14-yr-old children from Beirut reported $11.9 \%$ prevalence rates of asthma, $23.1 \%$ of wheezing, $25.5 \%$ of allergic rhinitis and $11 \%$ of atopic eczema [5]. In 1993, asthma was also one of the most common chronic diseases in the general population treated in primary healthcare facilities in Lebanon (2.9\%) [6].

Conversely, occupational use of pesticides in Lebanon is as common as agricultural working $(\sim 10 \%$ of the Lebanese population) [7]. Pesticides most commonly used include organophosphates, pyrethroids, biperidyl derivatives and dithiocarbamates [8]. House and yard pesticide treatments are commonly used in Lebanon, either by family members or by professionals, to fight against numerous insects.

Children of pesticide workers may be exposed through occupational sources (storing working equipment in the house, contamination of clothes, etc.) [9-12]. Residing near pesticidetreated areas or in agricultural regions also contributes to exposure to children [11-15]. House and yard pesticide treatments are associated with childrens' exposure to pesticides [11]. Outdoor spraying of pesticides poses the obvious risk of inhalation, although pesticide inhalation also occurs indoors [16]. In fact, direct indoor application of pesticides contaminates the house and exposes its occupants to volatile ingredients and residues [17]. Young children may be highly exposed to indoor and outdoor toxic substances, including pesticides, due to their proximity to potentially contaminated surfaces and air, in addition to their specific physiological characteristics, such as large skin surface:body mass ratio, increased sensitivity of cholinergic receptors to some pesticides, etc. [16]. This makes them more susceptible to the effects of pesticides [18-20]. Routine application of pesticides, whether by certified applicators or by direct use on pets could lead to continued accumulation on toys, pillows and other adsorbent surfaces, which can become a long-term source of exposure to any child [21, 22].

Moreover, pesticides are associated with respiratory diseases in adults, whether or not they live in an agricultural environment [23-26]. Children living in a rural setting might be exposed to agricultural pesticides and irritants responsible for asthma development [27]. In contrast, lower rates of allergic diseases have been reported in children living in rural areas, without a clear explanation [28]. In addition, a lower risk of asthma was found among farmers' children [29].

To the current authors' knowledge, there are currently no studies reporting a direct association between childrens' exposure to pesticides and respiratory disease or symptoms, and this study could therefore help to answer this question. The primary objective is to assess the association of paraoccupational, domestic or residential exposure to pesticides, with chronic respiratory diseases and symptoms observed among Lebanese children.

\section{Materials and methods}

\section{Study subjects}

Children in primary classes of Lebanese public schools, aged 5-16 yrs, were targeted.

\section{Study design}

This is a cross-sectional study, assessing association of declared chronic respiratory symptoms and diseases (asthma in particular) with exposure to pesticides. 


\section{Methods}

Schools were randomly selected from previously established lists of Lebanese schools [30]. Proportionate sampling was carried out, according to the number of schools in each Lebanese district: 19 schools were selected and only one school from Mount Lebanon refused to participate. Therefore, 18 schools from all Lebanese districts consented to participate: two in Beirut and suburbs, four in Mount Lebanon, six in the North, three from the Bekaa plain and three in the South. School directors were informed, and agreed to distribute questionnaires to all the children in primary classes.

From March to June 2000, parents were asked to fill in a questionnaire regarding their child's health in the local language, which was taken from the validated questionnaire of chronic respiratory diseases by the American Thoracic Society [31]; this questionnaire had already been adapted and tested in comparable subjects [32]. No further information was given regarding the exact objective of the study. All questionnaires were filled in by the parents and returned to school directors; incomplete questionnaires were sent back to the parents to be fully completed. Questionnaires were finally collected back by the researcher.

\section{Variables}

Regarding exposure to pesticides, answers to the following questions were considered: "has a member of the household ever used pesticides in his work?", "has a member of the household ever used pesticides for house or garden treatment?", "does your child live in a region heavily treated by pesticides?", "does he/she live in the proximity of a field heavily treated by pesticides?"

Exposure to pesticides was then divided into residential, para-occupational and domestic. Residential exposure was characterised by residing in the proximity of a treated field, in addition to the regions of dwelling. Domestic exposure included domestic use by a household member or treatment of the house and garden by a professional. Para-occupational exposure was due to the occupational use of pesticides by one of the household members. It was assessed by the declaration of the parents, while revision according to the type of profession was performed later on. Occupations considered exposed to pesticides included the following: pesticide applicator, agricultural worker, farmer and wood preservative painter. A variable summarising all types of exposure was built; it was positive whenever the child had one or more types of exposure to pesticides and negative whenever exposure to pesticides of any kind was not present.

Quantitative assessment of exposure was also carried out when possible. Cumulative exposure duration in declared days of exposure was calculated for domestic exposure. An expert in agronomy classified the regions according to the annual level of pesticide consumption. A score of $0-9$ was created, 0 corresponding to areas with no use of agricultural pesticides and 9 to areas with extensive pesticide use. Residential exposure was then characterised by the declared number of exposure years multiplied by the score of the area in question, or by 9 if the individual declared living near a treated field, respectively characterising the duration and intensity of exposure.

Health outcome variables corresponding to chronic respiratory diseases were reported by parents. Children were classified as having a chronic respiratory disease if they had recurrent cough or expectoration more than three times a week and more than three months a year, or if they had recurrent wheezing or more than one episode of dyspnoea and wheezing. Confirmation of asthma diagnosis by a doctor was used to ascertain parent reports. Questions were asked about the presence, type and treatment of allergy, if there were any. This was assessed by the following question: "has your doctor ever told you that your child is allergic to certain substances?"

Other variables taken into account were sex, age, reported height and weight, calculated body mass index in $\mathrm{kg} \cdot \mathrm{m}^{-2}$, passive smoking defined by number of smokers at home, socioeconomic status characterised by the father's and mother's educational level, and reported family respiratory diseases.

\section{Sample size calculation}

The sample size was calculated considering a minimal odds ratio (OR) of 2, 5\% $\alpha$ and $20 \% \beta$ errors, with a $5 \%$ prevalence of asthma [33] and a 10\% probability of exposure to pesticides within the general population [7]. With these assumptions, the minimal sample size required was $n=2,800$ individuals.

\section{Statistical analysis}

Bilateral statistical tests were used as follows: the Chisquared test for dichotomous or multinomial qualitative variables, the Mann Whitney U-test for quantitative variables with nonhomogeneous variances or non-normal distribution and the Student t-test for quantitative variables of normal distribution and homogeneous variances. Regarding multivariate analysis, a descendant stepwise logistic regression was performed and adjustment over potential confounding variables was carried out. The latter are variables known to be risk factors for respiratory diseases or that are unevenly distributed between groups of comparison $(\mathrm{p}<0.20)$.

\section{Results}

A total of 4,644 questionnaires were distributed in the 18 schools. Altogether, 3,852 (83\%) were returned but 561 were secondarily eliminated due to incomplete filling, resulting in 3,291 (71\%) filled questionnaires. Proportions of filled questionnaires ranged from $27 \%$ in schools in Akkar (Northern Lebanon) to $92.3 \%$ in schools in Kabbelias (Bekaa). In table 1 , the number of valuable questionnaires is presented. It should be noted that the response rate by region varies between $68.8 \%$ in Northern Lebanon and $84.5 \%$ in the Bekaa.

A chronic respiratory disease was reported in 407 (12.4\%) children; 84 out of 407 had a medically confirmed asthma diagnosis, constituting $2.6 \%$ of the population (table 1). Among 865 children (26.3\%), information from the questionnaire regarding their respiratory symptoms did not allow a conclusion about their respiratory health to be made. Comparisons were made with the 407 children with chronic respiratory disease diagnosis and the 2,016 children with no respiratory symptoms. A subgroup analysis was undertaken with $84(4 \%)$ asthmatic and 2,016 healthy children $(96 \%)$, in addition to the analysis of separate respiratory symptoms.

Children residing in northern Lebanon were more prone to chronic respiratory diseases, while those in Beirut had a lower prevalence $(p<0.001)$; the same result was found with respect to asthma $(p<0.01)$. The prevalence of different respiratory symptoms are also presented (table 1).

Social and demographic characteristics are presented in table 2 . Small but statistically significant differences regarding age and body mass index were noted. Children with respiratory diseases tend to look more aged $(\mathrm{p}=0.02)$ and have a 
Table 1.-Distribution of questionnaires and prevalence of respiratory symptoms in the areas of Lebanon

\begin{tabular}{|c|c|c|c|c|c|c|c|c|}
\hline Region & $\begin{array}{c}\text { Total } \\
\text { valuable }\end{array}$ & $\begin{array}{c}\text { No } \\
\text { disease }\end{array}$ & $\begin{array}{l}\text { Respiratory } \\
\text { disease }^{* * *}\end{array}$ & $\begin{array}{l}\text { Chronic } \\
\text { cough* }\end{array}$ & $\begin{array}{l}\text { Chronic } \\
\text { phlegm** }\end{array}$ & $\begin{array}{c}\text { Recurrent } \\
\text { wheezing** }\end{array}$ & $\begin{array}{c}\text { Ever } \\
\text { wheezing** }\end{array}$ & $\begin{array}{l}\text { Medical } \\
\text { asthma }\end{array}$ \\
\hline Beirut & $345(69.0)$ & $255(73.9)$ & $21(6.1)$ & $51(15.1)$ & $25(7.4)$ & $15(4.4)$ & $26(7.7)$ & $4(1.2)$ \\
\hline Mount & 330 (71.7) & $230(69.7)$ & $50(15.2)$ & $50(15.5)$ & $24(7.3)$ & $37(11.3)$ & $51(15.5)$ & $8(2.4)$ \\
\hline North & $1081(68.8)$ & $578(53.5)$ & $180(16.7)$ & $310(29.7)$ & $118(11.5)$ & $140(13.5)$ & $196(19.0)$ & $40(3.7)$ \\
\hline Bekaa & $1008(84.5)$ & 609 (60.4) & $86(8.5)$ & 209 (21.2) & $82(8.5)$ & $62(6.3)$ & $114(11.8)$ & $17(1.7)$ \\
\hline South & $547(76.0)$ & 344 (62.9) & $70(12.8)$ & $132(24.6)$ & $51(9.4)$ & $53(9.7)$ & 78 (14.3) & $15(2.7)$ \\
\hline Total & $3291(70.9)$ & $2016(61.3)$ & $407(12.4)$ & $752(23.2)$ & $300(9.4)$ & $307(9.5)$ & 465 (14.4) & $84(2.6)$ \\
\hline
\end{tabular}

Data are presented as n (\%). Beirut: Beirut and suburbs, schools of Salma Sayegh, Ghbeire; Mount: Mount Lebanon, schools of Haret Nehme, Kfarselouan, Amatour; North: North Lebanon, schools of Ibn Sina, Loukman, Menieh-Blat, Kfarhazir, Batroun, Akkar; Bekaa: Schools of Taalabaya, Bakkifa, Kabbelias; South: southern Lebanon, schools of Nabatieh, Alahd Jadid, Islah. ${ }^{\#}:$ response rate. *: $\mathrm{p}=0.05 ;{ }^{* *}: \mathrm{p}<0.01$; $* * *: \mathrm{p}<0.001$

higher body mass index $(\mathrm{p}=0.04)$. No statistically significant differences were noted regarding sex distribution and parents' education. Passive smoking was significantly more frequent in children with respiratory diseases. Moreover, allergy distribution, pet raising and playing with dust were also differently distributed $(\mathrm{p}<0.05)$; allergies were correlated to the respiratory disease $(\mathrm{OR}=5.41(4.04-7.23))$ and asthma $(\mathrm{OR}=7.59$ (5.17-11.13)). Family respiratory diseases history was also found to be associated with these symptoms; maternal and paternal respiratory diseases were significantly correlated to the child's respiratory disease $(\mathrm{OR}=2 ; \mathrm{p}<0.001)$ (table 2$)$.

The crude associations between exposure to pesticides and respiratory symptoms and diseases are presented in table 3. Residential exposure was associated with respiratory diseases $(p<0.001)$, especially with asthma $(p<0.001)$, as well as domestic exposure $(\mathrm{p}<0.001$ and $\mathrm{p}<0.05$, respectively). Para-occupational exposure was also associated with respiratory diseases $(\mathrm{p}<0.001)$ and asthma $(\mathrm{p}<0.001)$. Furthermore, the variable "any exposure" was correlated to the respiratory disease, with an $\mathrm{OR}=1.82(\mathrm{p}<0.001)$, and to asthma with an $\mathrm{OR}=1.73(\mathrm{p}=0.03)$. Single symptoms are associated with all exposure types, except for chronic cough which does not show any association with exposure to pesticides (table 3 ).
Logistic regression results are presented in table 4 . In the final model, retained variables were sex, age, body mass index, mother's or father's respiratory diseases, animal possession, and the number of smokers at home. Adjusted OR $\left(\mathrm{OR}_{\mathrm{a}}\right)$ for different types of exposure were still statistically significant. In addition to exposure to pesticides, only the number of smokers at home and the mother's respiratory disease were associated with the child's respiratory disease $\left(\mathrm{OR}_{\mathrm{a}}=1.2\right.$, $\mathrm{p}=0.02$; and $\mathrm{OR}_{\mathrm{a}}=2, \mathrm{p}<0.01$, respectively). Multivariate analysis for asthma and chronic respiratory symptoms was also performed, with comparable results; any type of exposure was significantly associated with asthma and respiratory symptoms, except for chronic cough (table 4).

In table 5, respiratory symptoms and disease associations with urban or rural areas were tested, with no significant association found ( $\mathrm{p}>0.05$, regardless of exposure to pesticides).

Multivariate analysis of cumulative exposure index correlation to respiratory diseases also led to statistically significant results, confirming the dose-effect relationship; subsequent quartile classes of cumulative domestic exposure were significantly correlated to respiratory disease $\left(\mathrm{OR}_{\mathrm{a}}=1.23 ; \mathrm{p}=0.03\right)$. This was also found for residential exposure $\left(\mathrm{OR}_{\mathrm{a}}=1.28\right.$; $\mathrm{p}=0.04$ ) (data not shown).

Table 2. - Social and demographic characteristics

\begin{tabular}{|c|c|c|c|}
\hline Variable & No respiratory symptom & Respiratory disease & p-value \\
\hline Subjects & 2016 & 407 & \\
\hline Age yrs & $9.79 \pm 2.29$ & $10.11 \pm 2.38$ & 0.02 \\
\hline $5-7$ & $307(18.2)$ & $54(16.8)$ & 0.50 \\
\hline $8-9$ & $491(29.1)$ & $84(26.1)$ & \\
\hline $10-11$ & $589(34.9)$ & $118(36.6)$ & \\
\hline $12-16$ & $303(17.9)$ & $66(20.5)$ & \\
\hline \multicolumn{4}{|l|}{ Sex } \\
\hline M & $1147(57.1)$ & $248(61.7)$ & 0.09 \\
\hline $\mathrm{F}$ & 861 (42.9) & $154(38.3)$ & \\
\hline BMI & $18.25 \pm 8.22$ & $19.12 \pm 9.14$ & 0.04 \\
\hline Home smokers & $1.21 \pm 0.93$ & $1.46 \pm 1.06$ & $<0.001$ \\
\hline Pet raising & $280(13.9)$ & $84(20.6)$ & $<0.001$ \\
\hline Playing with dust & $476(23.6)$ & $153(37.6)$ & $<0.001$ \\
\hline Allergy & $136(6.7)$ & $114(28.0)$ & $<0.001$ \\
\hline \multicolumn{4}{|l|}{ Father's education } \\
\hline$<8$ yrs school & $1073(56.4)$ & $223(59.2)$ & 0.56 \\
\hline$>8$ yrs school & 747 (39.2) & $140(37.1)$ & \\
\hline University & $84(4.4)$ & $14(3.7)$ & \\
\hline \multicolumn{4}{|l|}{ Mother's education } \\
\hline$<8$ yrs school & 994 (51.9) & $216(56.1)$ & 0.31 \\
\hline$>8$ yrs school & $849(44.3)$ & $155(40.3)$ & \\
\hline University & $74(3.9)$ & $14(3.6)$ & \\
\hline Father lung disease & $204(10.1)$ & $73(17.9)$ & $<0.001$ \\
\hline Mother lung disease & $169(8.4)$ & $70(17.2)$ & $<0.001$ \\
\hline
\end{tabular}

Data are presented mean \pm SD or as n (\%). M: male; F: female; BMI: body mass index. 
Table 3. - Types of exposure to pesticides and respiratory problems

\begin{tabular}{|c|c|c|c|c|c|}
\hline Exposure type & Subjects $n$ & Residential & Domestic & Para-occupational & Any exposure \\
\hline No symptom & 2016 & $386(19.1)$ & $1258(62.3)$ & $140(7.1)$ & $1281(63.4)$ \\
\hline Respiratory disease & 407 & $140(35.3)$ & $299(73.5)$ & $58(14.6)$ & $311(77.8)$ \\
\hline OR & & $1.21^{* * *}$ & $1.67 * * *$ & $2.24 * * *$ & $1.82 * * *$ \\
\hline $95 \% \mathrm{CI}$ & & $(1.74-2.82)$ & $(1.31-2.24)$ & $(1.59-3.15)$ & $(1.40-2.37)$ \\
\hline Asthma & 84 & $31(36.9)$ & $62(73.8)$ & $15(18.5)$ & $63(75.0)$ \\
\hline OR & & $2.47 * * *$ & $1.70^{*}$ & $2.98 * * *$ & $1.73^{*}$ \\
\hline $95 \% \mathrm{CI}$ & & $(1.52-4.01)$ & $(1.01-2.90)$ & $(1.58-5.56)$ & $(1.02-2.96)$ \\
\hline Chronic cough & 752 & $142(19.7)$ & $404(55.8)$ & $68(9.4)$ & $511(68.0)$ \\
\hline OR & & 1.17 & 1.08 & 1.20 & 1.11 \\
\hline $95 \% \mathrm{CI}$ & & $(0.94-1.46)$ & $(0.91-1.08)$ & $(0.88-1.62)$ & $(0.92-1.33)$ \\
\hline Chronic phlegm & 300 & $81(27.9)$ & $193(66.6)$ & $51(17.6)$ & $230(76.7)$ \\
\hline OR & & $1.94 * * *$ & $1.76^{* * *}$ & $2.67 * * *$ & $1.76^{* * *}$ \\
\hline $95 \% \mathrm{CI}$ & & $(1.45-2.58)$ & $(1.35-2.30)$ & $(1.88-3.79)$ & $(1.32-2.36)$ \\
\hline Recurrent wheezing & 307 & $98(32.6)$ & $193(64.1)$ & $36(12.0)$ & $236(76.9)$ \\
\hline OR & & $2.53^{* * *}$ & $1.56^{* * *}$ & $1.57 * * *$ & $1.78^{* * *}$ \\
\hline $95 \%$ CI & & $(1.93-3.33)$ & $(1.20-2.01)$ & $(1.06-2.33)$ & $(1.34-2.38)$ \\
\hline Ever wheezing & 465 & $139(30.6)$ & $293(64.1)$ & $52(11.5)$ & $356(76.6)$ \\
\hline OR & & $2.43^{* * *}$ & $1.60^{* * *}$ & $1.57^{* *}$ & $1.80^{* * *}$ \\
\hline $95 \% \mathrm{CI}$ & & $(1.93-3.07)$ & $(1.29-1.98)$ & $(1.12-2.20)$ & $(1.42-2.28)$ \\
\hline
\end{tabular}

Data are presented as n (\%) unless otherwise stated. Residential: regional exposure or near a treated field; domestic: domestic use by a household member or treatment of the house and garden by a professional; para-occupational: occupational use by a household member; any exposure: residential, domestic or para-occupational exposure; OR: odds ratio. CI: confidence interval. *: $\mathrm{p}<0.05 ; * *: \mathrm{p}<0.01 ; * * *: \mathrm{p}<0.001$.

Table 4.-Exposure to pesticides and respiratory problems: multivariate analysis

\begin{tabular}{|c|c|c|c|c|}
\hline Exposure type & Residential & Domestic & Para-occupational & Any exposure \\
\hline \multicolumn{5}{|c|}{ Respiratory disease } \\
\hline $\begin{array}{l}\mathrm{OR}_{\mathrm{a}} \\
95 \% \mathrm{CI}\end{array}$ & $\begin{array}{c}1.82 * * * \\
(1.28-2.59)\end{array}$ & $\begin{array}{c}1.77 * * * \\
(1.28-2.43)\end{array}$ & $\begin{array}{c}1.85^{* *} \\
(1.13-3.02)\end{array}$ & $\begin{array}{c}1.71 * * \\
(1.20-2.43)\end{array}$ \\
\hline \multicolumn{5}{|l|}{ Asthma } \\
\hline $\begin{array}{l}\mathrm{OR}_{\mathrm{a}} \\
95 \% \mathrm{CI}\end{array}$ & $\begin{array}{c}2.10^{*} \\
(1.01-4.42)\end{array}$ & $\begin{array}{c}1.99^{*} \\
(1.00-3.99)\end{array}$ & $\begin{array}{c}4.61^{* * *} \\
(2.06-10.29)\end{array}$ & $\begin{array}{c}1.73 * * \\
(1.02-2.97)\end{array}$ \\
\hline \multicolumn{5}{|l|}{ Chronic cough } \\
\hline $\begin{array}{l}\mathrm{OR}_{\mathrm{a}} \\
95 \% \mathrm{CI}\end{array}$ & $\begin{array}{c}1.17 \\
(0.86-1.59)\end{array}$ & $\begin{array}{c}1.00 \\
(0.79-1.28)\end{array}$ & $\begin{array}{c}0.95 \\
(0.62-1.45)\end{array}$ & $\begin{array}{c}1.04 \\
(0.82-1.33)\end{array}$ \\
\hline \multicolumn{5}{|l|}{ Chronic phlegm } \\
\hline $\begin{array}{l}\mathrm{OR}_{\mathrm{a}} \\
95 \% \mathrm{CI}\end{array}$ & $\begin{array}{c}1.59^{*} \\
(1.03-2.45)\end{array}$ & $\begin{array}{c}1.96^{* * * *} \\
(1.32-2.92)\end{array}$ & $\begin{array}{c}2.56^{* * * *} \\
(1.56-4.21)\end{array}$ & $\begin{array}{c}1.90 * * \\
(1.26-2.87)\end{array}$ \\
\hline \multicolumn{5}{|c|}{ Recurrent wheezing } \\
\hline $\begin{array}{l}\mathrm{OR}_{\mathrm{a}} \\
95 \% \mathrm{CI}\end{array}$ & $\begin{array}{c}2.73^{* * *} \\
(1.85-4.05)\end{array}$ & $\begin{array}{c}1.49^{*} \\
(1.03-2.16)\end{array}$ & $\begin{array}{c}1.57^{*} \\
(0.92-2.72)\end{array}$ & $\begin{array}{c}2.10^{* * *} \\
(1.39-3.18)\end{array}$ \\
\hline \multicolumn{5}{|l|}{ Ever wheezing } \\
\hline $\begin{array}{l}\mathrm{OR}_{\mathrm{a}} \\
95 \% \mathrm{CI}\end{array}$ & $\begin{array}{c}2.55^{* * *} \\
(1.84-3.52)\end{array}$ & $\begin{array}{c}1.50 * * \\
(1.12-2.01)\end{array}$ & $\begin{array}{c}1.73^{*} \\
(1.09-2.74)\end{array}$ & $\begin{array}{c}1.99 * * * \\
(1.43-2.78)\end{array}$ \\
\hline
\end{tabular}

Adjustments were made for passive smoking, sex, age, weight and body mass index, father's and mother's respiratory disease, father's and mother's educational levels, animal raising, and playing with dust. Residential: regional exposure or near a treated field; domestic: domestic use by a household member or treatment of the house and garden by a professional; para-occupational: occupational use by a household member; any exposure: residential, domestic or para-occupational exposure; $\mathrm{OR}_{\mathrm{a}}$ : adjusted odds ratio. CI: confidence interval. *: $\mathrm{p}<0.05 ; * *: \mathrm{p}<0.01 ; * * *: \mathrm{p}<0.001$.

\section{Discussion}

An association was found between exposure to pesticides and the report of chronic respiratory symptoms and disease, particularly asthma, among children from Lebanese public schools.

It is difficult to be sure whether the sample represents all public school children in different regions, since no such numbers are available. However, selection bias was limited by school randomisation and the good response rate $(>75 \%)$. Information about nonresponding parents could not be obtained, but the authors have no reason to presume that these parents in particular had children with respiratory diseases without exposure to pesticides. Since parents were not aware of the exact objective of the study, there is no reason to believe that the status of exposure would affect their response, especially because several types of exposure were considered.

It is accepted that subjects with self-reported asthma may show at least some lung dysfunction and this lends credibility to the idea that the subject would have clinical asthma [23]. The questionnaire of the American Thoracic Society that was used, which has been previously validated for epidemiological studies [34], is now considered a convenient way to classify individuals into cases and controls within large populations [35]. While studying asthma, the best question is a direct inquiry of whether the subject has, or has had, asthma [36]. A differential classification bias is thus unlikely. 
Table 5.-Respiratory symptoms and disease associations with urban or rural areas

\begin{tabular}{lccccccc}
\hline Area type & Subjects $n$ & Chronic cough & Chronic phlegm & Recurrent wheezing & Ever wheezing & Asthma & Respiratory disease \\
\hline Urban & 1447 & $339(24.9)$ & $133(9.4)$ & $146(10.2)$ & $213(14.9)$ & $60(4.1)$ & $187(17.2)$ \\
Rural & 1844 & $413(22.8)$ & $167(9.3)$ & $161(8.9)$ & $252(14.0)$ & $75(4.1)$ & $220(16.4)$ \\
OR & & 0.94 & 0.99 & 0.86 & 0.93 & 0.98 & 0.94 \\
$95 \%$ CI & & $0.80-1.12$ & $0.77-1.27$ & $0.67-1.10$ & $0.76-1.14$ & $0.68-1.41$ & $0.76-1.18$ \\
\hline
\end{tabular}

Data are presented as n (\%) unless otherwise stated. OR: odds ratio; CI: confidence interval.

The use of a cross-sectional design could introduce an information bias, since temporality is difficult to ascertain and recall bias is possible. Regarding lung function, bronchial responsiveness tests, atopy measurement and exposure to pesticides, the lack of objective data provided by the questionnaire should be taken into account, as this could lead to a nondifferential information bias, reducing the results towards the null. The low prevalence of doctor-confirmed asthma found in Beirut (1.2\%, table 2$)$ in comparison to that of the ISAAC study performed in $1998(11.9 \%)$ [5] could be explained by the fact that the population came from public schools only, where children are less likely to seek medical care because of their generally low socioeconomic status. In the ISAAC study, the prevalence of chronic wheezing was found to be $23.1 \%$, which is also higher than observed in the present study $(4.4 \%)$. This could be explained by the low sensitivity of the questionnaire, leading to a nondifferential information bias. However, it was noted that the results are comparable to those found in some Mediterranean regions, with a prevalence of asthma in West Bank Palestinian school children of 2.8-4.2\% [37], Arab school children living in Israel $4.9 \%$ [38] and Turkish children 2.8\% [39].

A parallel between exposure to pesticides and the spatial distribution of respiratory effects was observed, due to the increase in respiratory disease prevalence in agricultural regions with a higher use of pesticides (table 1). A doseeffect relationship was also demonstrated.

Multivariate analysis was performed, taking into consideration the main confounding factors. However, environmental exposure to different pollutants and allergens associated with asthma, in relation to urban life or rural setting (toxic substances, pollens, animal and fungal allergens, etc.), was impossible to assess with a questionnaire and its role in confounding the association with residential exposure to pesticides cannot be excluded. However, the analysis of urban versus rural area association with respiratory diseases and symptoms gave nonsignificant results. Moreover, the association between air pollution and asthma is not yet well established, and pollenosis prevalence is no higher in rural than urban areas [17]. Furthermore, these factors do not affect the association with domestic use of pesticides.

To the current authors knowledge, there are little epidemiological studies directly related to the effects of environmental exposure to pesticides and respiratory effects on children. In the Community Canvass Survey in the Prairie Ecosystem Study (PECOS) study, whose aim, in part, was to understand the short-term effects of environmental pesticides on lung function, the most commonly reported health diseases for children aged $<18$ yrs were a history of bronchitis (19.8\%), asthma $(10.2 \%)$ or skin allergies $(9.7 \%)$ [40]. Several incidents occurred where people, including children, living near to fumigant-treated surfaces experienced respiratory symptoms [41]. With paraquat drifts, several symptoms were reported, such as cough, rhinitis, dyspnoea and wheezing [42, 43].

The biological plausibility of the obtained results is illustrated by toxicological and clinical findings. Most pesticides are small molecules and they can exacerbate atopic patients and aggravate asthma and dermatitis symptoms by type-I and
-IV hypersensitivity mechanisms [44]. Apart from hypersensitivity, the detoxification or reparation capacity of the cells may be overwhelmed, again resulting in the development of respiratory diseases [45]. In addition, pesticides could affect respiration by systemic effects (neuromuscular and immune). In massive intoxication, they are responsible for causing laryngeal and bronchial constriction, central respiratory failure, and respiratory muscles weakness [46].

Central respiratory diseases caused by nicotine and rotenoids have been reported [41]. Exposure to organophosphates may be related to respiratory diseases in children, through deregulation of the autonomic nervous system by their anticholinesterase activity $[19,41]$. Conversely, pyrethroid derivatives are allergens, causing asthma-like attacks and anaphylactic reactions [41].

For further research, exposure assessment by sample analysis would be useful; experience to date has already shown that it is possible to measure childrens' multi-pathway exposure to pesticides [20]. If confirmed, the results obtained here could encourage a greater control of indoor air quality and education regarding outdoor exposure and indoor pesticide use [17, 47].

In conclusion, chronic exposure to pesticides in children was moderately associated with chronic respiratory symptoms and diseases, especially asthma. This study was particularly conclusive for indicators of para-occupational and residential exposures and the domestic use of pesticides.

\section{References}

1. Asher MI, Keil U, Anderson HR, et al. International Study of Asthma and Allergies in Childhood (ISAAC): rationale and methods. Eur Resp J 1995; 8: 843-491.

2. Al-Ghamdy YS, AL-Haddad NS, Adelgadir MH, Qureshi NA, Saleh MA, Khalil MM. Socioclinical profile of children with asthma in Al-Majmaah Health province. Saudi Med J 2000; 21: 847-851.

3. Zacharasiewicz A, Zidek T, Haidinger G, et al. Indoor factors and their association to respiratory symptoms. Wien Klin Wochenschr 1999; 111: 882-886.

4. von Mutius E. The environmental predictors of allergic diseases. J Allerg Clin Immunol 2000; 105: 9-19.

5. Ramadan F, Khoury M, Hajjar T, Mroueh S. Prevalence of allergic diseases among children in Beirut: comparison to worldwide data. Leb Med J 1999; 47: 216-221.

6. Adib S, Nuwayhed I, Hamadeh G. Most common diseases treated in primary health care facilities in Lebanon. Leb Med J 1995; 43: 17-22.

7. Central Statistics Administration. Household conditions in 1997, number 9. CSA, Beirut, 1998.

8. Geahchan A, Abi Zeid Daou A. Photosanitary Products Repertory. Beirut, APL, 1995.

9. Simcox NJ, Fenske RA, Wolz SA, Lee IC, Kalman DA. Pesticides in household dust and soil: exposure pathways for children of agricultural families. Environ Health Perspect 1995; 103: 1126-1134.

10. Gladen B, Sandler D, Zahm S, Kamel F, Rowland A, 
Alavanja M. Exposure opportunities of families of farmer pesticide applicators. Am J Ind Med 1998; 34: 581-587.

11. Azaroff LS. Biomarkers of exposure to organophosphorus insecticides among farmers' families in rural El Salvador: factors associated with exposure. Environ Res 1999; 80: $138-147$.

12. Lu C, Fenske RA, Simcox NJ, Kalman DA. Exposure to pesticides of children in an agricultural community: evidence of household proximity to farmland and take home exposure pathways. Environ Res 2000; 84: 290-302.

13. Loewenherz C, Fenske RA, Simcox NJ, Bellamy G, Kalman D. Biological monitoring of organophosphorous exposure to pesticides among children of agricultural workers in central Washington state. Environ Health Perspect 1997; 105: 1344-1353.

14. Fenske RA, Kissel JC, Lu C, et al. Biologically based pesticide dose estimates for children in an agricultural community. Environ Health Perspect 2000; 108: 515-520.

15. Koch D, Lu C, Fisker-Andersen J, Jolley L, Fenske RA. Temporal association of children's exposure to pesticides and agricultural spraying: report of a longitudinal biological monitoring study. Environ Health Perspect 2002; 110: 829-833.

16. Sanborne M, Cole D, Abelsohn A, Weir E. Identifying and managing adverse environmental health effects: 4 . Pesticides. CMAJ 2002; 166: 1431.

17. American Thoracic Society. Achieving healthy indoor air Am J Resp Crit Care Med 1998; 156: S33-S64.

18. Landrigan PJ, Claudio L, Markowitz SB. Pesticides and inner-city children: exposures, risks, and prevention. Environ Health Perspect 1999; 107: 431-437.

19. Eskenazi B, Bradman A, Castorina R. Exposures of children to organophosphates pesticides and their potential adverse health effects. Environ Health Perspect 1999; 107: 409-419.

20. Quackenboss J, Pellizzari E, Shubat P, et al. Design strategy for assessing multipathway exposure for children: the Minessota Children's Exposure to pesticides Study (MNCPES). J Exp Anal Environ Epidemiol 2000; 10: 145-158.

21. Gurunathan S, Robson M, Freeman N, et al. Accumulation of chlorpyrifos on residential surfaces and toys accessible to children. Environ Health Perspect 1998; 106: 9-16.

22. Davis DL, Ahmed AK. Exposures from indoor spraying of chlorpyrifos pose greater health risks to children than currently estimated. Environ Health Perspect 1998; 106: 299-301.

23. Senthilselvan A, McDuffie HH, Dosman JA. Association of asthma with use of pesticides. Am Rev Resp Dis 1992; 1466: 884-847.

24. Bener A. Respiratory symptoms, skin disorders and serum IgE levels in farm workers. Allerg Immunol Paris 1999; 31: $52-56$.

25. Sprince NL, Lewis MQ, Whitten PS, Reynols SJ, Zwerling C. Respiratory symptoms: associations with pesticides, silos and animal confinement in the Iowa Farm Family Health and Hazard Surveillance Project. Am J Ind Med 2000; 38: 455-462.

26. Ohayo-Mitoko GJ, Kromhout H, Simwa J, Boleij J, Heederik D. Self reported symptoms and inhibition of acetylcholinesterase activity among Kenyan agricultural workers. Occup Environ Med 2000; 57: 195-200.

27. Weinburg EG. Urbanization and childhood asthma: an African perspective. J Allerg Clin Immunol 2000; 105: 224-231.
28. Braun-Fahrlander Ch. Allergic diseases in farmers' children Ped Allerg Immunol 2000; 11: 19-22.

29. Klintberg B, Berglund N, Lilja G, Wickman M, van HageHamsten M. Fewer allergic respiratory disorders among farmers' children in a closed birth cohort from Sweden. Eur Resp J 2001; 17: 1151-1157.

30. Pedagogic Center for Research and Development. Guide of Schools for Public Teaching 1997-1998. PCRD, Beirut, 1998.

31. Ferris BG. Epidemiology standardization project. Am Rev Resp Dis 1978; 118: 1-88.

32. Salameh P. Acts of the first Franco-Lebanese Congress for Environment and Health. Beirut, Lebanese University, Faculty of Public Health, 1999.

33. Weinberger S, Drazen J. Disturbances of Respiratory Function. In: Harrisson's Principles of Internal Medicine, 13th edn. USA, McGraw-Hill Inc., 1994; pp. 1152-1159.

34. Senthilselvan A, Dosman JA, Chen Y. Relationship between pulmonary test variables and asthma and wheezing: a validation of self-report of asthma. J Asthma 1993; 30: 185-193.

35. Hogstedt C, Ingvar L. Epidemiology of occupational neurobehavioral hazards. Methodological experiences from organic solvent research. Rev Epidemiol Santé Publique 1992; 40: S7-S16.

36. Seaton A, Crompton G. Asthma: clinical features. In: Respiratory diseases, 5th Ed. USA, 2000; pp. 77-922.

37. Hasan MM, Gofin R, Bar-Yishay E. Urbanization and the risk of asthma among schoolchildren in the Palestinian Authority. J Asthma 2000; 37: 353-360.

38. Shohat T, Green MS, Davidson Y, Livne I, Tamir R, Garty BZ. Differences in the prevalence of asthma and current wheeze between Jews and Arabs: results from a national survey of schoolchildren in Israel. Ann Allerg Asthma Immunol 2002; 89: 386-392.

39. Turktas I, Selcuk ZT, Kalyoncu AF. Prevalence of asthmaassociated symptoms in Turkish children. Turk $J$ Pediatr 2001; 43: 1-11.

40. Masley ML, Semchuk KM, Senthilselvan A, et al. Health and Environment of rural families: results of a Community Canvass Survey in the Prairie Ecosystem Study (PECOS) J Agr Saf Health 2000; 6: 103-115.

41. Ecobichon D. Toxic Effects of Pesticides. In: Casarett \& Doull's Toxicology: the Basic Science of Poisons. USA, Curtis D. Klaassen, McGraw-Hill edition, 1996: pp. 643689.

42. Goldman LR. Acute symptoms in persons residing near a field treated with soil fumigants methyl bromide and chloropicrin. Pub Health 1987; 147: 95-98.

43. Ames A, Howd R, Doherty L. Community exposure to paraquat drift. Arch Environ Health 1993; 48: 47-51.

44. Vial T, Nicolas B, Descotes J. Clinical immunotoxicity of pesticides. J Toxicol Environ Health 1996; 48: 215-229.

45. Dinsdale D. Clinical and Experimental Toxicology of Organophosphates and Carbamates. Butterworth Heinemann, USA, 1992; pp. 156-166.

46. Do Pico G. Hazardous exposure and lung disease among farm workers. Occup Lung Dis 1992; 13: 311-328.

47. Persky V, Coover L, Hernandez E, et al. Chicago community-based asthma intervention trial. Chest 1999; 116: S216-S223. 